\title{
Identification of lipocalin-2 as a PKC $\delta$ phosphorylation substrate in neutrophils
}

\author{
Yi-Chinn Weng ${ }^{1}$, Guona Wang ${ }^{1}$, Robert O Messing ${ }^{2,3}$ and Wen-Hai Chou ${ }^{1,2^{*}}$
}

\begin{abstract}
Background: PKC $\delta$ expressed in neutrophils is implicated in promoting reperfusion injury after ischemic stroke. To understand the molecular and cellular actions of $P K C \delta$, we employed a chemical-genetics approach to identify PKC $\delta$ substrates in neutrophils.

Results: We recently generated knock-in mice endogenously expressing analog-specific PKC $\delta$ (AS-PKC $\delta$ ) that can utilize ATP analogs as phosphate donors. Using neutrophils isolated from the knock-in mice, we identified several PKC $\delta$ substrates, one of which was lipocalin-2 (LCN2), which is an iron-binding protein that can trigger apoptosis by reducing intracellular iron concentrations. We found that PKC $\delta$ phosphorylated LCN2 at T115 and this phosphorylation was reduced in $\mathrm{PrkCd}^{-1-}$ mice. PKC $\delta$ colocalized with LCN2 in resting and stimulated neutrophils. LCN2 release from neutrophils after cerebral ischemia was reduced in PKC $\delta$ null mice.
\end{abstract}

Conclusions: These findings suggest that PKC $\delta$ phosphorylates LCN2 and mediates its release from neutrophils during ischemia-reperfusion injury.

Keywords: PKC, Stroke, Neutrophil, Lipocalin-2, Phosphorylation

\section{Background}

Ischemic stroke is a leading cause of mortality and disability in the United States [1]. Early reperfusion with thrombolytic agents can be effective in treating acute ischemic stroke, but may initiate and enhance inflammatory responses causing reperfusion injury [2]. After reperfusion, neutrophils adhere to cerebral vasculature, infiltrate ischemic brain tissues, and release free radicals and proteins that may exacerbate brain injury [3]. Our prior work indicates that PKC $\delta$ is necessary for neutrophil activation following ischemia and reperfusion. We found that $P r k c d^{-/-}$mice show a striking $70 \%$ reduction in brain injury after ischemic stroke [4]. This outcome was associated with reduced infiltration of neutrophils into infarcted tissue, as well as impaired neutrophil adhesion, migration, respiratory burst, and degranulation. To further understand the molecular and cellular mechanisms by which PKC $\delta$ contributes to

\footnotetext{
* Correspondence: wchou2@kent.edu

${ }^{1}$ Department of Biological Sciences, School of Biomedical Sciences, Kent State University, Kent, $\mathrm{OH} 44224$, USA

2Department of Neurology, University of California, San Francisco, CA 94608 USA

Full list of author information is available at the end of the article
}

reperfusion injury, we aimed to identify $\mathrm{PKC} \delta$ substrates in neutrophils.

PKC constitutes a family of 10 serine-threonine kinases sharing a highly conserved catalytic domain [5]. Similarities in the catalytic domains of PKC isozymes make it difficult to identify the unique targets of an individual isozyme in the presence of related cellular kinases. A chemical-genetic approach has been developed to identify kinase substrates and specific kinase inhibitors by modifying the gatekeeper residue of catalytic domain to accept analogs of ATP and PP1 inhibitors that have low affinity for native kinases [6,7]. Using this approach we generated and characterized an analog-specific PKC $\delta$ (AS-PKC $\delta$ ) [8-10]. AS-PKC $\delta$ shows kinase activity similar to wild type PKC $\delta$, but can utilize $\mathrm{N}^{6}$-(benzyl)-ATP as a phosphate donor and is uniquely sensitive to inhibition by 1 NA-PP1 [8-10]. To identify PKC $\delta$ substrates in neutrophils, we wanted to express AS-PKC $\delta$ in neutrophils, but because they are terminally differentiated and difficult to transfect, we instead used AS-PKC $\delta$ knock-in mice, which endogenously express AS-PKC $\delta$ [10]. Using neutrophils isolated from these knock-in mice, we identified lipocalin-2 (LCN2) as a PKC $\delta$ substrate. $\mathrm{LCN} 2$, also known as oncogene $24 \mathrm{p} 3$, siderocalin or 
neutrophil gelatinase-associated lipocalin (NGAL), was initially purified as a $25 \mathrm{kDa}$ protein secreted from neutrophils [11]. Several pathological conditions including bacterial infection [12], renal ischemia [13], spinal cord injury [14], and ischemic stroke [15-17] trigger the release of LCN2. Here we found reduced release of LCN2 in Prkcd ${ }^{-/-}$mice following cerebral ischemia, indicating an important role for PKC $\delta$ in LCN2 secretion.

\section{Methods}

\section{Kinase assay}

Neutrophils were isolated from bone marrow by Percoll density gradient centrifugation $[4,18]$. Neutrophils were lysed by freeze/thaw treatment in modified RIPA buffer containing $50 \mathrm{mM}$ Tris- $\mathrm{HCl} \mathrm{pH} 7.4,150 \mathrm{mM} \mathrm{NaCl}, 1 \%$ NP-40, 5 mM EDTA, 5 mM EGTA, phosphatase inhibitor cocktails I and II (Sigma-Aldrich), and cOmplete ${ }^{\mathrm{TM}}$ protease inhibitor cocktail (Roche), and were centrifuged at $20,000 \mathrm{~g}$ for $15 \mathrm{~min}$ at $4^{\circ} \mathrm{C}$. The supernatant $(100 \mu \mathrm{g}$ proteins) was incubated in $60 \mu$ of PKC reaction buffer containing $20 \mathrm{mM}$ HEPES $\mathrm{pH} 7.4,0.1 \mathrm{mM}$ EGTA, $0.03 \%$ Triton $\mathrm{X}-100$, and $10 \mathrm{mM} \mathrm{MgCl}_{2}$ at $27^{\circ} \mathrm{C}$ for $30 \mathrm{~min}$ with $1 \mathrm{mM}$ GTP, $200 \mu \mathrm{M} \mathrm{N} \mathrm{N}^{6}$-(benzyl)-ATP- $\gamma \mathrm{S}$ (Biolog), and $1 \mu \mathrm{M}$ phorbol 12-myristate 13-acetate (PMA) (Sigma-Aldrich) to initiate the reaction. Control reactions without PMA, and reactions with $1 \mu \mathrm{M}$ 1NA-PP1 (Calbiochem) to inhibit AS-PKC $\delta$ activity were included. The kinase reactions were stopped by adding $20 \mathrm{mM}$ EDTA. Thiophosphorylated proteins were alkylated by incubation with $2.5 \mathrm{mM}$ para-nitrobenzylmesylate (PNBM) (Epitomics) for $2 \mathrm{~h}$ at room temperature.

\section{Fractionation by MicroSol-IEF}

Alkylated proteins were resolved by isoelectric focusing using a Zoom-IEF Fractionator (Invitrogen), according to the manufacturer's protocol [19]. Alkylated samples were dissolved in IEF fractionation buffer containing $7 \mathrm{M}$ urea, $2 \mathrm{M}$ thiourea, 4\% CHAPS (Invitrogen), $65 \mathrm{mM}$ DTT, 1 mM EDTA, protease inhibitors cocktail (Roche), and $1 \mathrm{mM}$ PMSF (Sigma-Aldrich), and centrifuged at $20,000 \mathrm{~g}$ for $60 \mathrm{~min}$ at $4^{\circ} \mathrm{C}$. The supernatant was collected to determine the protein concentration by the Bradford protein assay using BSA as a standard and were adjusted with IEF fractionation buffer to $0.6 \mathrm{mg} / \mathrm{mL}$. Aliquots of $650 \mu \mathrm{l}$ were loaded in five different $\mathrm{pH}$ chambers $(\mathrm{pH}$ 3.0-4.6, $\mathrm{pH}$ 4.6-5.4, $\mathrm{pH}$ 5.4-6.2, $\mathrm{pH}$ 6.2-7.0, and $\mathrm{pH} 7.0-10.0)$ in the Zoom-IEF Fractionator, and processed sequentially at $100 \mathrm{~V}$ for $20 \mathrm{~min}, 200 \mathrm{~V}$ for $80 \mathrm{~min}$ and $600 \mathrm{~V}$ for $80 \mathrm{~min}$. The fractionated samples from each chamber were analyzed by western blot analysis using rabbit monoclonal antibodies against the thiophosphate esters (1:10,000 dilution; Abcam) and HRP conjugated secondary antibodies (1:1,000 dilution; Jackson ImmunoResearch). Gel loading was assessed by western blot analysis with a mouse monoclonal anti-actin antibody (1:2,000 dilution; Sigma-Aldrich).

MALDI-TOF mass spectrometry for protein identification Protein bands of interest detected on western blots were excised from parallel Coomassie Blue stained gels and placed into microcentrifuge tubes. The gel slices were dried in a vacuum concentrator, rehydrated and digested in trypsin solution $(12.5 \mathrm{ng} / \mu \mathrm{l}$ sequencing grade trypsin in freshly diluted $25 \mathrm{mM}$ ammonium bicarbonate) overnight at $32^{\circ} \mathrm{C}$. The liquid containing trypsinized peptides was extracted twice with $50 \mu \mathrm{l}$ of $50 \%$ acetonitrile/2\% TFA. The combined extracts were dried and resuspended in matrix solution $(10 \mathrm{mg} / \mathrm{ml}$ 4-hydroxy- $\alpha$-cyanocinnamic acid in 50\% acetonitrile/0.1\% TFA). Matrix-Assisted Laser Desorption/Ionization Time-of-Flight (MALDI-TOF) mass spectrometric analysis was performed on the digest using a PerSeptive Voyager DE-RP mass spectrometer in the linear mode by Applied Biomics, Hayward, CA. Detected peptides were analyzed by peptide mass fingerprinting using the Mascot search engine [20].

\section{Purification of recombinant LCN2}

A plasmid (kindly provided by M. Green, U. Mass. Med. School) containing the cDNA sequence encoding the mouse Lcn2 gene in pGEX-2T (GE Healthcare) was expressed in E. coli BL21(DE3)pLysS cells (Invitrogen) [21]. GST-LCN2 fusion protein was purified by affinity chromatography using Glutathione-Sepharose 4B beads (GE Healthcare). Purified GST-LCN2 was incubated with thrombin-agarose (Sigma-Aldrich) to remove the GST tag. The supernatant containing cleaved GST and LCN2 was incubated with Glutathione-Sepharose to absorb the GST. The supernatant containing only LCN2 was collected for in vitro kinase assays.

\section{In vitro kinase assay}

In vitro phosphorylation of purified LCN2 by recombinant PKC (Invitrogen) was performed as described [22]. The kinase reaction was initiated at $37^{\circ} \mathrm{C}$ by adding recombinant LCN2 and $\left[\gamma_{-}{ }^{32} \mathrm{P}\right] \mathrm{ATP}$. At different time points, the reaction mixture was stopped by the addition of SDS sample buffer. Proteins were separated on NuPAGE Bis-Tris gels (Invitrogen) and stained using SimplyBlue (Invitrogen). Phosphorylated LCN2 was detected by phosphorimaging (Typhoon 9410, Amersham Bioscience).

\section{Mapping phosphorylation sites by tandem mass spectrometry}

To identify the PKC $\delta$ phosphorylation sites, LCN2 protein was phosphorylated in vitro by $\mathrm{PKC} \delta$ using $0.5 \mathrm{mM}$ non-radiolabeled ATP for $4 \mathrm{~h}$ as described above. The reaction mixtures were fractionated by SDS-PAGE and stained with SimplyBlue (Invitrogen). Gel slices containing 
the phosphorylated LCN2 were treated with trypsin, and the resulting peptide mixtures were analyzed by nanoliquid chromatography-mass spectrometry/mass spectrometry (nano-LC-MS/MS) serviced at the Protein Chemistry Center, UT Southwestern Medical Center. Samples from the digests were analyzed by nano-LC-MS/MS using a LC-Packings HPLC (Dionex) coupled to a QStar XL mass spectrometer (Applied Biosystems). Data were searched against a home-built database that includes the LCN2 sequence. Four modifications were included in the database search: carbamidomethyl $(\mathrm{C})$, oxidation $(\mathrm{M})$, phospho (ST), and phospho (Y).

\section{Generation of LCN2 phosphorylation site mutants}

LCN2 T115A was generated by site-directed mutagenesis using a QuikChange mutagenesis kit (Stratagene). The mouse Lcn2 cDNA subcloned into pGEX-2TK was used as a template to replace Thr-115 with Ala using the following primers: 5'-GCTCCAGGGCTGGCCAGTTC GCCCTGGGAAATATGCACAGG-3' (forward) and 5' -C CTGTGCATATTTCCCAGGGCGAACTGGCCAGCCC TGGAGC-3' (reverse). The coding region was sequenced to confirm error-free PCR and the T115A mutation. The LCN2 T115A protein was generated in E. coli BL21(DE3) pLys cells and purified as described above.

\section{Detection of LCN2 T115 phosphorylation by phospho-specific antibody}

A polyclonal rabbit anti-phospho-LCN2 (T115) antibody against a phosphopeptide ${ }^{110}$ RAGQF[pT]LGNMHR ${ }^{121}$ was generated and affinity-purified as a service at ProSci Inc. We optimized specificity for the targeted phosphoepitope using both negative and positive affinity purification methods, as described [23]. The phospho-LCN2 (T115) antibody (1:500 dilution) was used in western blotting to detect the phosphorylation of LCN2 in neutrophil lysates or LCN2 phosphorylated in vitro by PKC $\delta$ in the presence of non-radioactive ATP.

\section{Immunofluorescence}

Neutrophils were plated on glass coverslips coated with $20 \%$ fetal calf serum for $10 \mathrm{~min}$ at $37^{\circ} \mathrm{C}$. The coverslips with attached neutrophils were treated with or without $1 \mu \mathrm{M}$ formyl-Met-Leu-Phe (fMLP) for $10 \mathrm{~min}$ at $37^{\circ} \mathrm{C}$ and fixed in $2 \%$ paraformaldehyde in PBS for $10 \mathrm{~min}$ at room temperature [24]. After permeabilization in $0.1 \%$ Triton X-100 in PBS for 5 min, neutrophils were blocked in $10 \%$ normal donkey serum (NDS), $0.2 \%$ BSA in PBS for $1 \mathrm{~h}$ and incubated with mouse anti-PKC $\delta$ antibody (1:200 dilution; BD) and goat anti-LCN2 antibody (1:200 dilution; R\&D Systems) diluted in PBS containing 2\% NDS and $0.2 \%$ BSA overnight at $4^{\circ} \mathrm{C}$. After three washes with PBS, neutrophils were incubated with the appropriate Donkey fluorochrome-conjugated secondary antibodies
(1:200 dilution; Jackson ImmunoResearch) and coverslipped in mounting media containing DAPI (Vector Labs) to localize nuclei. Images were captured using Zeiss LSM 510 laser confocal microscope.

\section{Secretion of LCN2 in neutrophils}

Neutrophils were stimulated with $1 \mu \mathrm{M}$ of fMLP (Sigma-Aldrich) for 10, 20, 30, 60, and 120 min. Release and cell-associated LCN2 were analyzed by western blot analysis using anti-LCN2 antibody (R\&D Systems).

\section{Cerebral ischemia and reperfusion}

Global cerebral ischemia was induced by bilateral common carotid artery occlusion (BCCAO) without hypotension [25,26]. Mice weighing 25-35 g were anesthetized with $1.5 \%$ isoflurane in $30 \% \quad \mathrm{O}_{2} / 70 \% \quad \mathrm{~N}_{2}$ using the $\mathrm{V}-10$ Anesthesia system (VetEquip). Rectal temperature was maintained at $37 \pm 0.5^{\circ} \mathrm{C}$ throughout the procedure by the TR-200 homeothermic temperature system (Fine Science Tools). Both common carotid arteries were carefully dissected away from the vagus nerves and occluded with Micro Serrefines (Fine Science Tools). Following 10 min of occlusion, the Micro Serrefines were removed from the CCA to induce reperfusion. All procedures were conducted in accordance with Institutional Animal Care and Use Committee policies.

\section{Collection of mouse serum}

At different time points after $\mathrm{BCCAO}$, mice were anesthetized with $5 \%$ isoflurane and euthanized by cervical dislocation. The blood was collected from the decapitated trunk and placed at room temperature for one hour. The blood was centrifuged at $2000 \mathrm{~g}$ for $20 \mathrm{~min}$ at room temperature, and the supernatant was collected as blood serum for western blot analysis [27].

\section{Statistical analysis}

Quantitative data were expressed as mean \pm SEM and analyzed using Prism 5.0 (GraphPad). Two-tailed, unpaired $t$-test or ANOVA with post hoc tests was used to determine statistical significance between means. The value of $p$ less than 0.05 was considered to be statistically significant.

\section{Results}

\section{Identification of PKC $\delta$ substrates in neutrophils}

We found that only AS-PKC $\delta$, but not wild type PKC can use $\mathrm{N}^{6}$-(benzyl)-ATP in a kinase reaction with histone III as a substrate [8]. Previous studies have demonstrated the use of analog-specific kinases to identify substrates with ${ }^{32}$ P-labeled ATP analogs [28-33]. However, it remains challenging to isolate ${ }^{32} \mathrm{P}$-labeled substrates through conventional chromatography for identification by mass spectrometry. To facilitate the identification and purification of PKC $\delta$ substrates, we adopted an affinity tagging strategy 
to label substrates that can be recognized by a specific antibody [8]. First, an analog-specific kinase is used to thiophosphorylate substrates with $\mathrm{N}^{6}$-(benzyl)-ATP- $\gamma$ S. The thiophosphate groups are then alkylated by paranitrobenzylmesylate (PNBM) to create thiophosphate ester epitopes that can be detected with the antibody.

Using this method, we found several proteins were labeled in AS-PKC $\delta$ neutrophil lysates, but not in wild type lysates (Figure 1A). We purified some of these putative substrates by microscale solution isoelectric focusing (MicroSol-IEF) [19] and SDS-PAGE (Figure 1B and C). Coomassie blue-stained bands (Figure $1 C$ ) that matched immunoreactive bands (Figure 1B) were excised, and proteins in excised gels were identified by MALDI-TOF peptide mass fingerprint analysis. After a careful literature search to study known functions of these potential substrates and evaluate their potential contribution to understanding the role of $\mathrm{PKC} \delta$ in stroke-induced reperfusion injury, we decided to focus on LCN2, a $25 \mathrm{kDa}$ protein band identified in the fraction of pI 7-10 (Figure 1C). Previous studies have shown that LCN2 plays a vital role in apoptosis $[21,34]$ and the plasma concentration of LCN2 is elevated in patients suffering from ischemic stroke [15-17]. Understanding the role of PKC $\delta$-LCN2 signaling events may reveal an unidentified neuralimmune interaction contributing to the induction of neuronal apoptosis.

Identification of LCN2 T115 as the PKC $\delta$ phosphorylation site To investigate whether LCN2 is a direct substrate of PKC , we prepared recombinant LCN2 (Figure 2) and found that PKC $\delta$ phosphorylated LCN2 efficiently in in vitro kinase assays (Figure 3A). Nano-LC-MS/MS analysis of the phosphorylated and trypsin digested LCN2 identified a single phosphorylated peptide containing a threonine residue at 115 (in italics) (AGQFTLGNMHR; amino acids 111-121) (Figure 3B and C). To verify the PKC $\delta$ phosphorylation site, we generated a phosphorylation site mutant by mutating Thr- 115 into Ala (T115A) and found that the T115A mutant is not phosphorylated by PKC $\delta$ (Figure 3D). A ribbon model of LCN2 (PDB number: 1X89) was generated using UCSF Chimera (http://www.cgl. ucsf.edu/chimera), and predicted that T115 is located in the solvent-accessible $\beta 5$ strand (Figure 3E) [35]. T115 and surrounding residues are well conserved between human, rat, and mouse homologs of LCN2 (Figure $3 \mathrm{~F}$ ) [36], suggesting a conserved role in function.

\section{Phosphorylation of LCN2 at T115 is reduced in neutrophils from Prkcd $^{-1}$ mice}

After identification of the $\mathrm{PKC} \delta$ phosphorylation site in vitro (Figure 3 ), we investigated whether PKC $\delta$ phosphorylates LCN2 in vivo. We prepared an affinity-purified, phospho-specific antibody raised against a peptide containing phospho-T115. This anti-phospho-LCN2 (T115) antibody specifically detected recombinant LCN2 phosphorylated by PKC $\delta$ in vitro, but not unphosphorylated LCN2 or LCN2 T115A (Figure 4A). Anti-phosphoLCN2 (T115) immunoreactivity was reduced by $25 \%$ in Prkcd ${ }^{-1-}$ neutrophils compared with wild type neutrophils (Figure $4 \mathrm{~B}$ and $\mathrm{C}$ ), consistent with the prediction that PKCS phosphorylates neutrophil LCN2 at T115 in vivo.

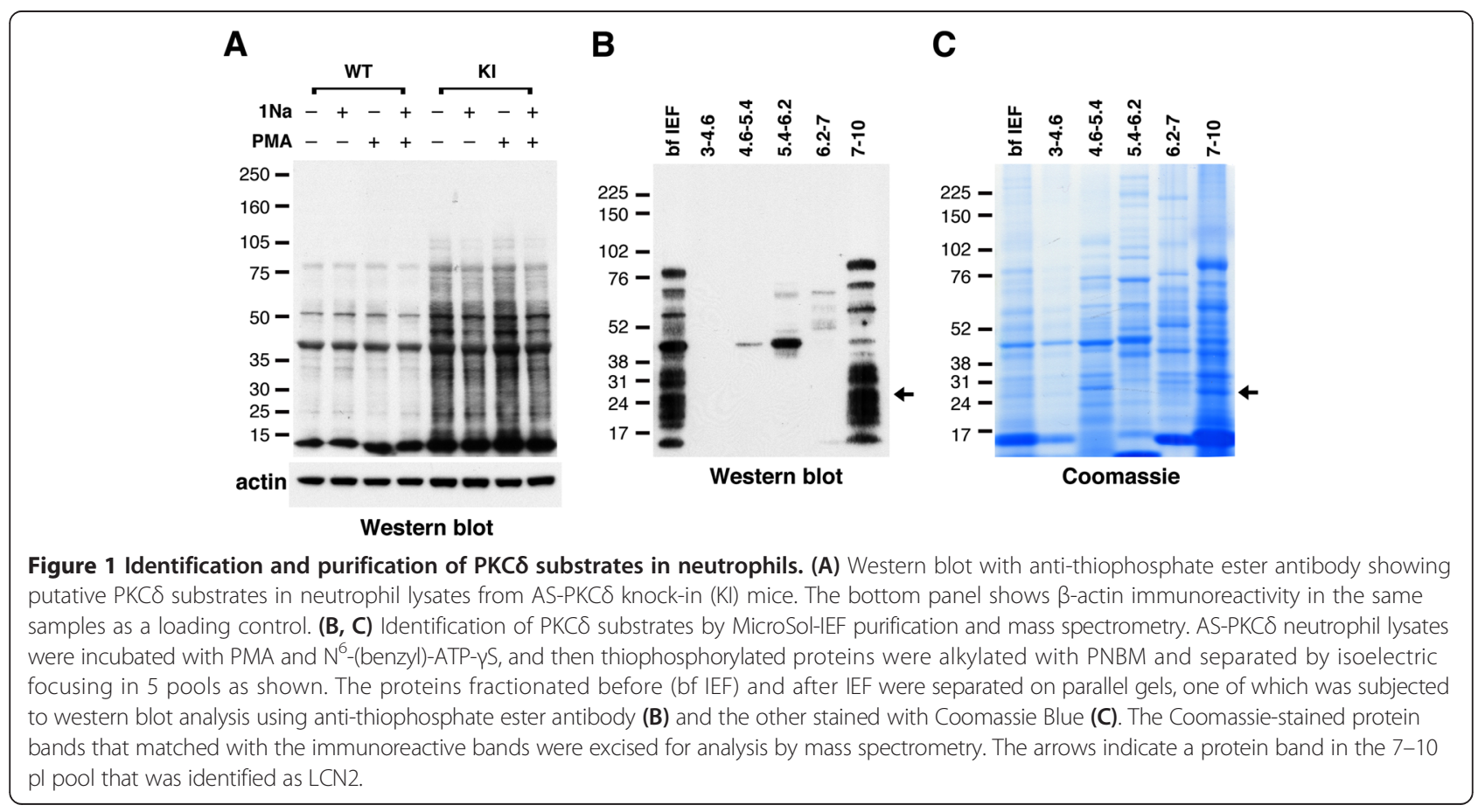




\section{A}

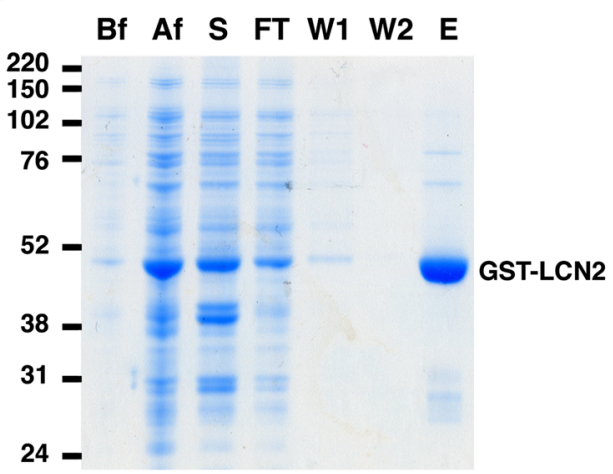

B

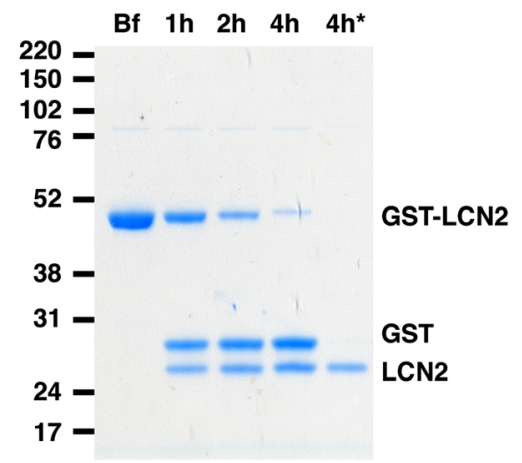

Figure 2 Purification of LCN2. (A) Recombinant GST-LCN2 was purified from E. coli BL21 by affinity chromatography using glutathione-sepharose 4B. Lysates from different purification steps were separated by SDS-PAGE: before (Bf) and after (Af) IPTG induction, supernatant after centrifugation (S), flow-through from column after loading supernatant (FT), 1st column wash (W1), 2nd column wash (W2), and elution of GST-LCN2 (E). (B) GST-LCN2 was digested by thrombin to remove the GST tag. GST-LCN2 was incubated with Thrombin-agarose (Sigma) at RT for up to $4 \mathrm{~h}$. After $4 \mathrm{~h}$ incubation, the cleaved GST was absorbed by glutathione-sepharose. The supernatant containing only LCN2 (4 h*) was collected.

\section{PKC $\delta$ colocalizes with LCN2 in neutrophils}

Since the integrity of subcellular compartments is lost during the preparation of cell lysates, it is important to demonstrate the colocalization of kinase and substrate in intact cells [37]. We performed immunofluorescence staining of neutrophils using antibodies against PKC $\delta$ and LCN2 (Figure 5). At baseline, PKC $\delta$ and LCN2 were diffusely distributed in the cell. Upon exposure to the fMLP chemoattractant, neutrophils took on a polarized morphology and initiated migration with F-actin enriched at the leading edge $[38,39]$. PKC $\delta$ was found mostly in the leading edge of polarized neutrophils [40] and LCN2 was detected at both poles. PKC $\delta$ and LCN2 colocalized with F-actin at the leading edge. The subcellular localization of LCN2 was previously determined by electron microscopic immunocytochemistry at high resolution, showing that LCN2 is present in the secondary vesicles (granules) and cytosol of neutrophils [41]. The presence of LCN2 in two different compartments is probably because LCN2 is a relatively small molecule $(25 \mathrm{kDa})$ and can leak from vesicles (granules) into the cytosol [41]. PKC $\delta$ has been detected in the cytosol of neutrophils [42] as well as in granule fractions after stimulation with opsonized zymosan [43]. Based on previous studies and our current findings, we think that the colocalization of PKC $\delta$ and LCN2 supports their relationship as kinase and substrate in neutrophils.

Release of LCN2 from neutrophils and after cerebral ischemia is reduced in $\mathrm{PrkCd}^{-/-}$mice

Previous studies demonstrated that the level of LCN2 in human plasma is elevated after ischemic stroke [15-17]. Since peripheral blood neutrophils are activated during the first few hours after stroke $[2,44]$, the elevated LCN2 in plasma is likely derived from activated neutrophils. We previously found that several measures of neutrophil activation are impaired in neutrophils from $\mathrm{PrkCd}^{-/-}$ mice [4]. We therefore hypothesized that LCN2 secretion would be impaired as well. To induce LCN2 secretion in vitro, we treated neutrophils with fMLP and found that the fMLP-stimulated release of LCN2 was reduced in $\mathrm{PrkCd}^{-/-}$neutrophils (Figure 6A). This result could not be explained by reduced abundance of LCN2, since LCN2 abundance was similar in wild type and $\mathrm{PrkCd}^{-1-}$ neutrophils (Figure 6A), suggesting that $\mathrm{PKC} \delta$ is involved in regulating the secretion but not the expression of LCN2. We then examined the level of LCN2 in the sera of wild type and $\mathrm{Prkcd}^{-/-}$mice after global cerebral ischemia (Figure 6B). Blood sera collected at different intervals after $10 \mathrm{~min}$ of bilateral common carotid artery occlusion (BCCAO) were subjected to western blot analysis for LCN2. The abundance of LCN2 immunoreactivity was low in the sera of mice not subjected to BCCAO. In wild type mice, the level of LCN2 increased one hour after $\mathrm{BCCAO}$, and increased progressively further at 4 and 24 hours. LCN2 induction after BCCAO was greatly reduced in $P r k c d^{-1-}$ mice, indicating a role of $\mathrm{PKC} \delta$ in mediating LCN2 release after cerebral ischemia.

\section{Discussion}

In this study, we employed a chemical-genetics approach to identify PKC $\delta$ substrates in neutrophils. One of the PKC $\delta$ substrates was LCN2, a member of the lipocalin family. PKC $\delta$ directly phosphorylates LCN2 at T115 in vitro and in neutrophils. The members of lipocalin family share little overall sequence homology, but all form a similar cup-shaped structure suited for carrying small hydrophobic molecules [36]. The crystal structure 


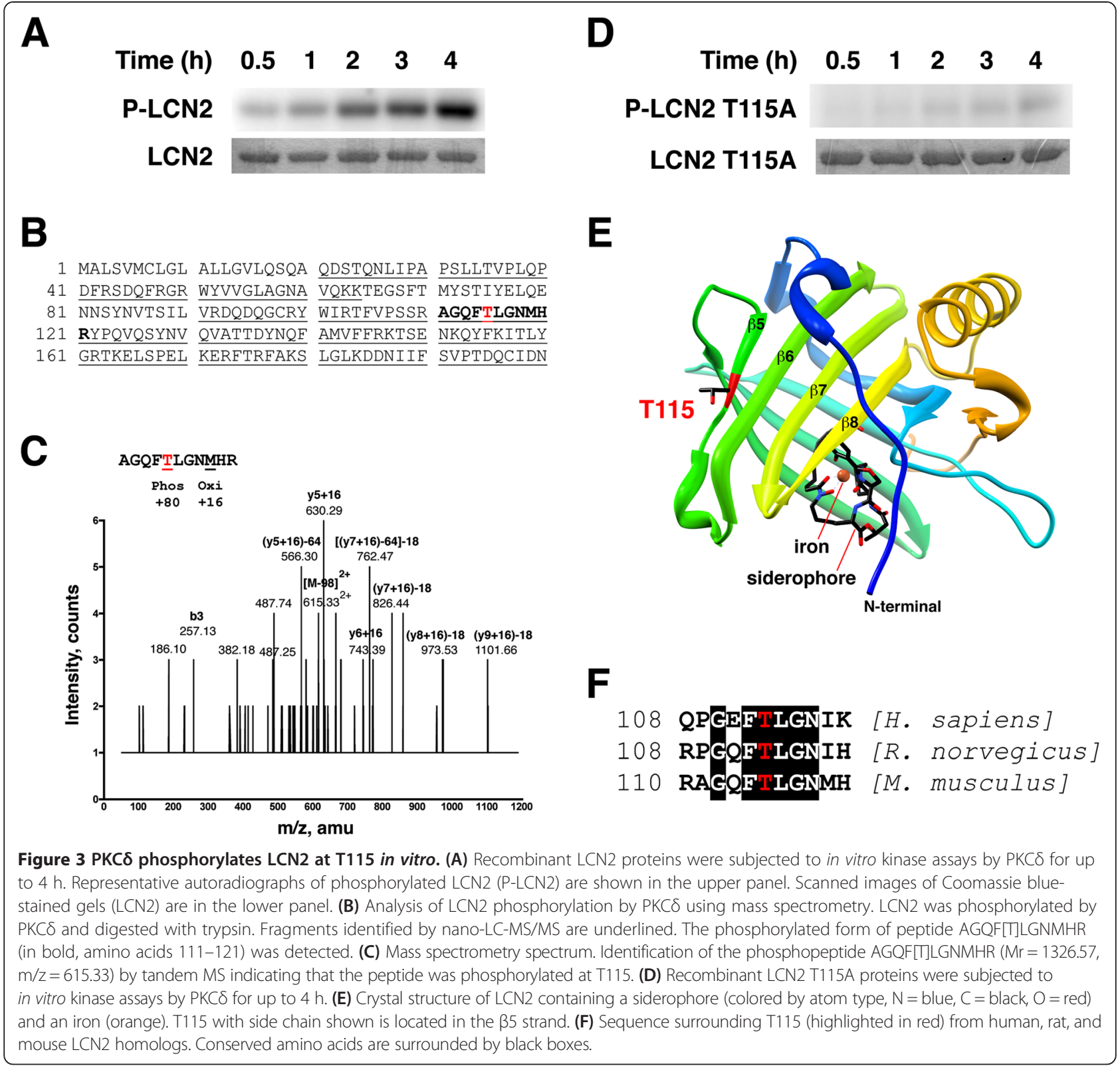

of LCN2 with nine $\beta$-strands and one $\alpha$-helix forms a funnel-like binding pocket containing an iron-loaded siderophore [35] (Figure 3E). The PKC $\delta$ phosphorylation site (T115) is not located within the siderophore-binding pocket, but on the $\beta 5$ strand with its side chain projecting outward. Thus, phosphorylation of T115 is unlikely to alter the binding with the siderophore, but instead could regulate the interaction of LCN2 with other molecules.

The anti-phospho-LCN2 (T115) immunoreactivity was significantly reduced in the neutrophil lysates of Prkcd $^{-1-}$ mice (Figure 4). However, the presence of residual immunoreactivity in Prkcd ${ }^{-/-}$mice suggests that T115 might also be phosphorylated by other kinases. There are three additional PKC isozymes $(\alpha, \beta, \zeta)$ found expressed in neutrophils $[4,42,43]$. The preferred amino acid sequences flanking the phosphorylated residue for each PKC isozyme have been determined as isozyme specific phosphorylation motifs $[45,46]$. The four PKC isozymes $(\alpha, \beta, \delta, \zeta)$ in neutrophils all prefer phosphorylating peptides with a hydrophobic residue at position +1 of the phosphorylated site towards the carboxyl-terminal $[45,46]$. The amino acid following Thr-115 of LCN2 fits that criterion with Leu at this position (Figure 3B). PKC $\alpha$ and $\delta$, but not $\mathrm{PKC} \beta$ and $\zeta$, prefer Arg at -5 position. Only $\mathrm{PKC} \delta$, but not other neutrophil PKC's, prefers hydrophobic residues at $+2,+3$ 


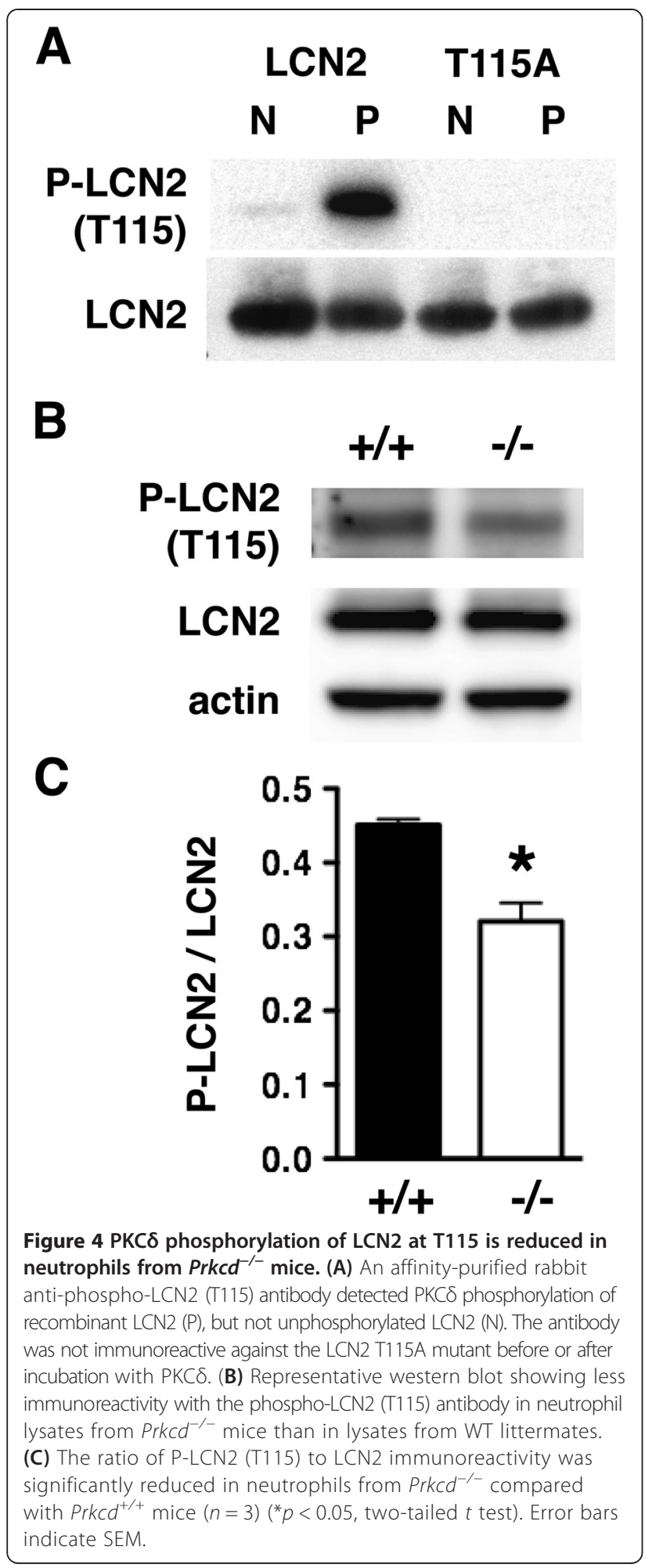

and +4 . The sequence flanking Thr-115 contains Arg at -5 and Met at +4 , so Thr -115 may be preferentially phosphorylated by PKC $\delta$. However, the sequence lacks a basic residue at the -3 position, and thus it is not fully conserved as a PKC $\delta$ specific phosphorylation motif. These linear phosphorylation motifs are short peptide sequences derived from in vitro kinase assays using an oriented peptide library $[45,46]$. Thus, predictions based on motifs are suggestive, but may not fully capture the phosphorylation events in vivo. In fact, recent studies demonstrate that PKC and PKA phosphorylate Ser/Thr residues of substrates within sequences that do not match known linear motifs [47]. The folding of different parts of the substrate can create "structurally formed" phosphorylation motifs. LCN2 exists as a monomer and homodimer as well as heterodimer with MMP-9 [36,48]. The tertiary and quaternary structures of LCN2 may contribute to the specificity of substrate phosphorylation by PKCס. Future studies will be needed to decipher the mechanisms in detail.

We found that LCN2 is released from fMLP-stimulated neutrophils in vitro and into the serum after cerebral ischemia (Figure 6). Previous studies demonstrate that LCN2 is up-regulated in mouse models of spinal cord injury [14] and neurodegeneration [49]. Neutrophil infiltration, expression of pro-inflammatory chemokines and cytokines, and neuronal cell death after spinal cord injury [14] are reduced in LCN2 null mice. We recently found that brain injury, neurological deficits, and infiltration of immune cells were markedly diminished in LCN2 null mice when compared with wild type mice after strokereperfusion injury [50]. Recombinant LCN2 stimulates neutrophil migration in vitro and in vivo [51] and induces apoptosis by sequestering intracellular iron [21,34]. Moreover, stroke patients with higher LCN2 levels in blood plasma show higher cardiovascular mortality [17]. These findings suggest that LCN2 is a chemoattractant for neutrophils and a pro-inflammatory signal induced by nervous system injury. Our previous study shows that neutrophil infiltration and brain injury are reduced in Prkcd ${ }^{-1-}$ mice after ischemic stroke [4]. Given our current results showing that LCN2 release is reduced in $\mathrm{Prkcd}^{-/-}$ mice, the mild stroke phenotype in $\operatorname{Prkcd}^{-1-}$ mice may result in part from reduced release of LCN2. Taken together, our results suggest that reduction of PKC $\delta$ activation and LCN2 release might prove useful in reducing post-ischemic inflammation and brain injury after stroke.

\section{Conclusions}

Neutrophil PKC $\delta$ contributes to stroke-reperfusion injury, but the underlying mechanisms remain to be determined. In this report, we identified lipocalin- 2 as a PKC $\delta$ substrate in neutrophils using a chemical-genetics approach. PKC $\delta$ phosphorylates lipocalin-2 at T115 and mediates the secretion of lipocalin-2 in neutrophils. This study provides a potential mechanism for the role of $\mathrm{PKC} \delta$ in stroke-reperfusion injury. 


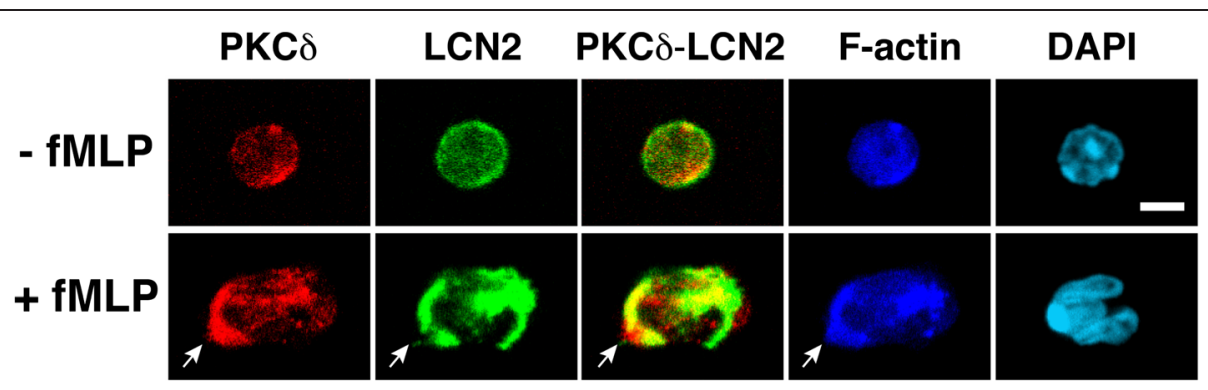

Figure 5 Colocalization of PKC $\delta$ and LCN2 in neutrophils. Neutrophils treated with or without fMLP were stained with specific antibodies against PKC (red) and LCN2 (green). Merged images (yellow) indicate colocalization of PKC $\delta$ and LCN2. Phalloidin staining (dark blue) revealed the reorganization of F-actin and polarization of neutrophils. An arrow indicates the front edge of the neutrophil that is enriched with F-actin. DAPI (light blue) was used to detect nuclei. Scale bars, $10 \mu \mathrm{m}$.

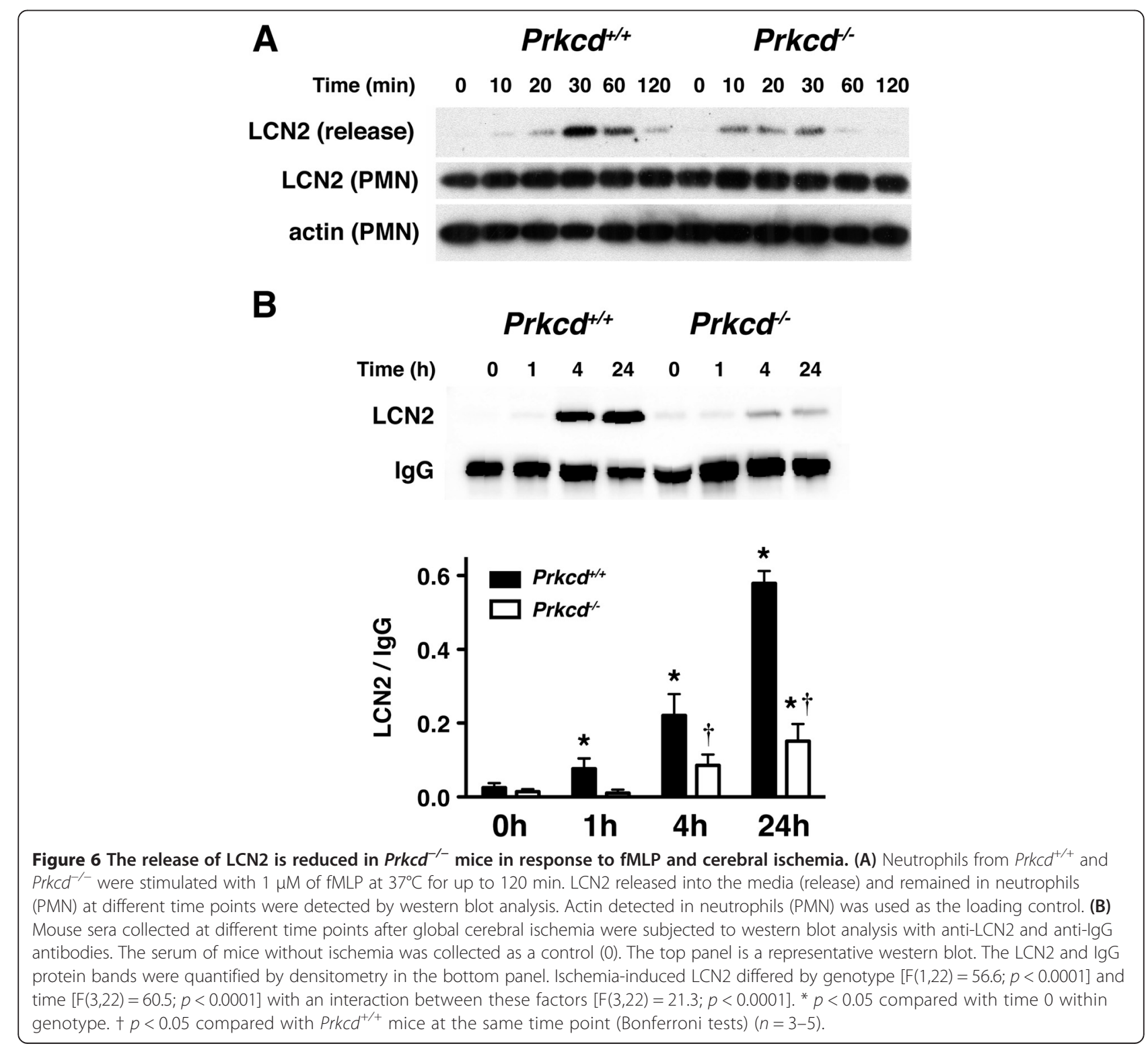




\section{Competing interests}

The authors declare that they have no competing interests.

\section{Authors' contributions}

WHC conceived, directed and funded the study. WHC, YCW, and GW designed experiments and analyzed data. YCW, GW, and WHC performed the experiments. WHC, ROM and YCW wrote the manuscript. All authors read and approved the final version of the manuscript.

\section{Acknowledgements}

This work was supported by NIH Grant NS057195, UCSF REAC grant, Kent State University start-up fund, AHA 13BGIA13820011, and Farris Family Innovation Award to W.C. Chou, and by NIH grant R01 AA018316 to R.O. Messing. We thank Professor M. Green at University of Massachusetts Medical School for the GST-LCN2 CDNA constructs, T.C. Chiang, and M. Rosen for technical support.

\section{Author details}

${ }^{1}$ Department of Biological Sciences, School of Biomedical Sciences, Kent State University, Kent, OH 44224, USA. '2Department of Neurology, University of California, San Francisco, CA 94608, USA. ${ }^{3}$ Division of Pharmacology and Toxicology, College of Pharmacy, The University of Texas at Austin, Austin, TX 78712, USA.

\section{Received: 17 December 2014 Accepted: 13 March 2015 Published online: 20 March 2015}

\section{References}

1. Go AS, Mozaffarian D, Roger VL, Benjamin EJ, Berry JD, Borden WB, et al. Heart disease and stroke statistics-2013 update: a report from the American Heart Association. Circulation. 2013;127:e6-245.

2. ladecola C, Anrather J. The immunology of stroke: from mechanisms to translation. Nat Med. 2011;17:796-808.

3. Eltzschig HK, Eckle T. Ischemia and reperfusion-from mechanism to translation. Nat Med. 2011;17:1391-401.

4. Chou WH, Choi DS, Zhang H, Mu D, McMahon T, Kharazia VN, et al. Neutrophil protein kinase Cdelta as a mediator of stroke-reperfusion injury. J Clin Invest. 2004;114:49-56.

5. Steinberg SF. Structural basis of protein kinase C isoform function. Physiol Rev 2008;88:1341-78.

6. Bishop AC, Buzko O, Shokat KM. Magic bullets for protein kinases Trends Cell Biol. 2001;11:167-72.

7. Zhang C, Lopez MS, Dar AC, Ladow E, Finkbeiner S, Yun CH, et al. Structure-guided inhibitor design expands the scope of analog-sensitive kinase technology. ACS Chem Biol. 2013;8:1931-8.

8. Allen JJ, Li M, Brinkworth CS, Paulson JL, Wang D, Hubner A, et al. A semisynthetic epitope for kinase substrates. Nat Methods. 2007:4:511-6.

9. Choi DS, Wei W, Deitchman JK, Kharazia VN, Lesscher HM, McMahon T, et al Protein kinase Cdelta regulates ethanol intoxication and enhancement of GABA-stimulated tonic current. J Neurosci. 2008:28:11890-9.

10. Kumar V, Weng YC, Geldenhuys WJ, Wang D, Han X, Messing RO, et al. Generation and Characterization of ATP Analog-specific Protein Kinase Cdelta. J Biol Chem. 2015;290:1936-51.

11. Kjeldsen $L$, Johnsen $A H$, Sengelov $H$, Borregaard N. Isolation and primary structure of NGAL, a novel protein associated with human neutrophil gelatinase. J Biol Chem. 1993;268:10425-32.

12. Flo TH, Smith KD, Sato S, Rodriguez DJ, Holmes MA, Strong RK, et al. Lipocalin 2 mediates an innate immune response to bacterial infection by sequestrating iron. Nature. 2004;432:917-21.

13. Mishra J, Dent C, Tarabishi R, Mitsnefes MM, Ma Q, Kelly C, et al. Neutrophil gelatinase-associated lipocalin (NGAL) as a biomarker for acute renal injury after cardiac surgery. Lancet. 2005;365:1231-8.

14. Rathore Kl, Berard JL, Redensek A, Chierzi S, Lopez-Vales R, Santos M, et al. Lipocalin 2 plays an immunomodulatory role and has detrimental effects after spinal cord injury. J Neurosci. 2011;31:13412-9.

15. Elneihoum AM, Falke $P$, Axelsson L, Lundberg E, Lindgarde F, Ohlsson K. Leukocyte activation detected by increased plasma levels of inflammatory mediators in patients with ischemic cerebrovascular diseases. Stroke. 1996;27:1734-8

16. Anwaar I, Gottsater A, Ohlsson K, Mattiasson I, Lindgarde F. Increasing levels of leukocyte-derived inflammatory mediators in plasma and CAMP in platelets during follow-up after acute cerebral ischemia. Cerebrovasc Dis. 1998:8:310-7.

17. Falke P, Elneihoum AM, Ohlsson K. Leukocyte activation: relation to cardiovascular mortality after cerebrovascular ischemia. Cerebrovasc Dis. 2000;10:97-101.

18. Lowell CA, Berton G. Resistance to endotoxic shock and reduced neutrophil migration in mice deficient for the Src-family kinases Hck and Fgr. Proc Natl Acad Sci U S A. 1998:95:7580-4.

19. Zuo X, Lee K, Ali-Khan N, Speicher DW. Protein profiling by microscale solution isoelectrofocusing (MicroSol-IEF). Curr Protoc Protein Sci. 2005; Chapter 22:Unit 22.26.

20. Perkins DN, Pappin DJ, Creasy DM, Cottrell JS. Probability-based protein identification by searching sequence databases using mass spectrometry data. Electrophoresis. 1999;20:3551-67.

21. Devireddy LR, Gazin C, Zhu X, Green MR. A cell-surface receptor for lipocalin 24p3 selectively mediates apoptosis and iron uptake. Cell. 2005;123:1293-305

22. Chou WH, Wang D, McMahon T, Qi ZH, Song M, Zhang C, et al. GABAA receptor trafficking is regulated by protein kinase C(epsilon) and the N-ethylmaleimide-sensitive factor. J Neurosci. 2010;30:13955-65.

23. Qi ZH, Song M, Wallace MJ, Wang D, Newton PM, McMahon T, et al. Protein kinase $C$ epsilon regulates gamma-aminobutyrate type A receptor sensitivity to ethanol and benzodiazepines through phosphorylation of gamma2 subunits. J Biol Chem. 2007;282:33052-63.

24. Pongracz J, Webb P, Wang K, Deacon E, Lunn OJ, Lord JM. Spontaneous neutrophil apoptosis involves caspase 3-mediated activation of protein kinase C-delta. J Biol Chem. 1999:274:37329-34

25. Zhen G, Dore S. Optimized protocol to reduce variable outcomes for the bilateral common carotid artery occlusion model in mice. J Neurosci Methods. 2007;166:73-80.

26. Bacigaluppi M, Comi G, Hermann DM. Animal models of ischemic stroke. Part two: modeling cerebral ischemia. Open Neurol J. 2010;4:34-8.

27. Thavasu PW, Longhurst S, Joel SP, Slevin ML, Balkwill FR. Measuring cytokine levels in blood. Importance of anticoagulants, processing, and storage conditions. J Immunol Methods. 1992;153:115-24.

28. Habelhah H, Shah K, Huang L, Burlingame AL, Shokat KM, Ronai Z. Identification of new JNK substrate using ATP pocket mutant JNK and a corresponding ATP analogue. J Biol Chem. 2001;276:18090-5.

29. Shah K, Shokat KM. A chemical genetic screen for direct v-Src substrates reveals ordered assembly of a retrograde signaling pathway. Chem Biol. 2002;9:35-47

30. Eblen ST, Kumar NV, Shah K, Henderson MJ, Watts CK, Shokat KM, et al. Identification of novel ERK2 substrates through use of an engineered kinase and ATP analogs. J Biol Chem. 2003;278:14926-35.

31. Ubersax JA, Woodbury EL, Quang PN, Paraz M, Blethrow JD, Shah K, et al. Targets of the cyclin-dependent kinase Cdk1. Nature. 2003;425:859-64.

32. Hindley AD, Park S, Wang L, Shah $K$, Wang $Y$, Hu X, et al. Engineering the serine/threonine protein kinase Raf-1 to utilise an orthogonal analogue of ATP substituted at the N6 position. FEBS Lett. 2004;556:26-34.

33. Larochelle S, Batliner J, Gamble MJ, Barboza NM, Kraybill BC, Blethrow JD, et al. Dichotomous but stringent substrate selection by the dual-function Cdk7 complex revealed by chemical genetics. Nat Struct Mol Biol. 2006;13:55-62.

34. Devireddy LR, Hart DO, Goetz DH, Green MR. A mammalian siderophore synthesized by an enzyme with a bacterial homolog involved in enterobactin production. Cell. 2010;141:1006-17.

35. Holmes MA, Paulsene W, Jide X, Ratledge C, Strong RK. Siderocalin (Len 2) also binds carboxymycobactins, potentially defending against mycobacterial infections through iron sequestration. Structure. 2005;13:29-41.

36. Kjeldsen L, Cowland JB, Borregaard N. Human neutrophil gelatinase-associated lipocalin and homologous proteins in rat and mouse. Biochim Biophys Acta. 2000;1482:272-83.

37. Cohen P. The origins of protein phosphorylation. Nat Cell Biol. 2002;4:E127-30.

38. Parent CA. Making all the right moves: chemotaxis in neutrophils and Dictyostelium. Curr Opin Cell Biol. 2004;16:4-13.

39. Wang F. The signaling mechanisms underlying cell polarity and chemotaxis. Cold Spring Harb Perspect Biol. 2009;1:a002980.

40. Lopez-Lluch G, Bird MM, Canas B, Godovac-Zimmerman J, Ridley A Segal AW, et al. Protein kinase C-delta C2-like domain is a binding site for actin and enables actin redistribution in neutrophils. Biochem J. 2001;357:39-47 
41. Kjeldsen L, Bainton DF, Sengelov H, Borregaard N. Identification of neutrophil gelatinase-associated lipocalin as a novel matrix protein of specific granules in human neutrophils. Blood. 1994;83:799-807.

42. Kent JD, Sergeant S, Burns DJ, MCPhail LC. Identification and regulation of protein kinase C-delta in human neutrophils. J Immunol. 1996;157:4641-7.

43. Sergeant S, MCPhail LC. Opsonized zymosan stimulates the redistribution of protein kinase C isoforms in human neutrophils. J Immunol. 1997;159:2877-85.

44. Jin R, Yang G, Li G. Inflammatory mechanisms in ischemic stroke: role of inflammatory cells. J Leukoc Biol. 2010;87:779-89.

45. Pearson RB, Kemp BE. Protein kinase phosphorylation site sequences and consensus specificity motifs: tabulations. Methods Enzymol. 1991;200:62-81.

46. Nishikawa K, Toker A, Johannes FJ, Zhou SY, Cantley LC. Determination of the specific substrate sequence motifs of protein kinase $C$ isozymes. J Biol Chem. 1997;272:952-60.

47. Duarte ML, Pena DA, Nunes Ferraz FA, Berti DA, Paschoal Sobreira TJ, Costa-Junior HM, et al. Protein folding creates structure-based, noncontiguous consensus phosphorylation motifs recognized by kinases. Sci Signal. 2014;7:ra105.

48. Yan L, Borregaard N, Kjeldsen L, Moses MA. The high molecular weight urinary matrix metalloproteinase (MMP) activity is a complex of gelatinase B/MMP-9 and neutrophil gelatinase-associated lipocalin (NGAL). Modulation of MMP-9 activity by NGAL. J Biol Chem. 2001;276:37258-65.

49. Bi F, Huang C, Tong J, Qiu G, Huang B, Wu Q, et al. Reactive astrocytes secrete Icn2 to promote neuron death. Proc Natl Acad Sci U S A. 2013;110:4069-74.

50. Wang G, Weng YC, Han X, Whaley JD, McCrae KR, Chou WH. Lipocalin-2 released in response to cerebral ischemia mediates reperfusion injury in mice. J Cell Mol Med. 2015 Feb 20. doi: 10.1111/jcmm.12538. [Epub ahead of print].

51. Schroll A, Eller K, Feistritzer C, Nairz M, Sonnweber T, Moser PA, et al. Lipocalin-2 ameliorates granulocyte functionality. Eur J Immunol. 2012;42:3346-57.

\section{Submit your next manuscript to BioMed Central and take full advantage of:}

- Convenient online submission

- Thorough peer review

- No space constraints or color figure charges

- Immediate publication on acceptance

- Inclusion in PubMed, CAS, Scopus and Google Scholar

- Research which is freely available for redistribution 